of necropsy examinations. All six patients had malignant disease-abdominal adenocarcinoma in four cases, bladder cancer in one, and Hodgkin's disease in one. Only one patient had symptoms referable to the heart; in the remainder neurological phenomena, shock, or recurrent pulmonary embolism predominated. The neurological component would in any case tend to dull the awareness of chest pain that is typical of coronary-artery occlusion. Nevertheless, myocardial infarction was the cause of death in three patients. Only one patient had clinical and laboratory evidence of disseminated intravascular coagulation.

This fresh series of cases once again emphasises the clinical concomitants of this thrombotic valve disease, the sometimes widespread embolic phenomena, and the relation to distant carcinomas of secretory tissue. The aetiology and pathogenesis of non-bacterial thrombotic endocarditis are still obscure, but the evidence points to some degree of intravascular coagulation. The significance of the condition depends on the primary cause; where this is deep-seated abdominal cancer the prognosis is very poor and the condition is little more than a clinical curiosity. Study of non-bacterial thrombotic endocarditis may, however, be important in shedding light on the clotting abnormalities found in malignant disease.

${ }^{1}$ British Medical fournal, 1967, 3, 812

${ }^{2}$ British Medical fournal, 1971, 3, 5.

${ }^{3}$ Goodnight, S H, Annals of the New York Academy of Sciences, 1974, 230, 271.

4 Lindström, F D. Flodmark, O, and Gustafsson, B, Acta Medica Scandinavica, 1977, 202, 203.

${ }^{5}$ Fayemi, A O, Deppisch, L M, American fournal of Clinical Pathology, $1977,68,393$.

\section{Epidemiology of ovarian cancer}

Cancer of the ovary causes more deaths than any other gynaecological disorder-about 4000 in Britain each year. The death rate has steadily increased during this century and is still rising among older women. ${ }^{1}$ Scrutiny of the rates shows that women born during this century have experienced fairly steady death rates (adjusted for age), but that these are higher than for women born towards the end of last century, and much higher than for those born earlier still. These changes may be partly due to better diagnosis, but perhaps they also reflect changes in life-style that occurred many years ago. Firmer evidence for an environmental cause comes from comparison of the current incidence of ovarian cancer in different countries with similar diagnostic facilities. Thus these neoplasms are common in most Western countries but rare in Japan, ${ }^{2}$ though when Japanese migrate to the United States their mortality begins to approach that of the host country. ${ }^{34}$

Attempts to discover the causes of ovarian cancer have been hampered by the large variety of histological types and the inability of pathologists to agree on their classification. It would be surprising if all the different kinds of ovarian cancer had the same aetiology. Nevertheless, the results of the US Third National Cancer Survey show that the common epithelial tumours do share some epidemiological features. ${ }^{56}$ Their incidence increases appreciably with age, and they are commoner among whites than blacks. They are also commoner among women who have never married.
The influences of marital status and parity have been disentangled in an elegant study by Joly et al, ${ }^{7}$ who showed that, while the risk was higher in single women, it was higher still among married women who had not borne children. Compared with controls, patients with ovarian cancer included more women who had tried to become pregnant but failed and more who had conceived only once or twice. The authors concluded that some factor was both depressing fertility and increasing the risk of ovarian cancer in these women.

The association with low parity has now been confirmed in another case-control study. ${ }^{8}$ One thought-provoking aspect of this study is that fewer of the patients with ovarian cancer reported using oral contraceptives. Unfortunately there were of defects in the methods for selecting and interviewing controls, $\overrightarrow{0}$ so that we are uncertain how much reliance we can place on $\vec{\overrightarrow{ }}$ this finding. If the difference is real it could be related to the lower fertility of women who develop cancer of the ovary: it would be helpful to know whether the patients with ovarian cancer also made less use of other contraceptive methods.

Another recent report from the United States suggested $\overrightarrow{0}$ that treatment with stilboestrol for menopausal symptoms :might increase the risk of ovarian cancer." This conclusion $\infty$ was based on small numbers, however, and a second study $\subseteq$ did not incriminate exogenous oestrogens. ${ }^{10}$

We still need more information about any effects of hormone preparations-before or after the menopause-on the risk of ovarian cancer. But drugs are unlikely to be the factor responsible for the apparent rise in incidence this centuryor the large geographical variation. Graham and Graham ${ }^{11}$ suggested that asbestos might be the culprit: a reasonable suspicion, since many ovarian tumours are ultimately of mesothelial origin, ${ }^{12} 13$ and the tendency of asbestos to cause peritoneal mesothelioma is well known. ${ }^{14}$ Nevertheless, there is little evidence to link asbestos with cancer of the ovary. Newhouse et $a l^{15}$ did find an excess of deaths from ovarian cancer among workers heavily exposed to asbestos, but the numbers were very small, and possibly peritoneal mesotheliomas could have been misdiagnosed as ovarian cancers (or vice versa).

Perhaps a more likely culprit is diet. Mortality from ovarian cancer in different countries correlates with several dietary variables, ${ }^{16}$ and dietary habits change when people migrate from Japan to the United States ${ }^{17}$ (and experience more $\delta$ ovarian cancer). Though dietary influences are difficult to assess, they certainly deserve attention in future studies.

${ }^{1}$ Office of Population Censuses and Surveys, Cancer Mortality, England

and Wales, 1911-1970. London, HMSO, 1975. Lyon, International Agency for Research on Cancer, 1976.

${ }^{3}$ Haenszel, W, and Kurihara, M, Fournal of the National Cancer Institute, 1968, 40, 43.

${ }^{4}$ Dunn, J E, Cancer Research, 1975, 35, 3240.
${ }_{5}$ Weiss, N S, Homonchuk, T, and Young, J L, Gynecologic Oncology, 1977, 5, 161

${ }^{6}$ Weiss, N S, Young, J L, and Roth, G J, fournal of the National Cancer Institute, 1977, 58, 913.

Joly, D J, et al, American fournal of Epidemiology, 1974, 99, 190.

Newhouse, M L, et al, British fournal of Preventive and Social Medicine, 1977, 31, 148.

${ }^{9}$ Hoover, R, Gray, L A, and Fraumeni, J F, Lancet, 1977, 2, 533.

10 Annegers, J F, O'Fallon, W, and Kurland, L T, Lancet, 1977, 2, 869.

11 Graham, J, and Graham, R, Environmental Research, 1967, 1, 115.

${ }^{12}$ Scully, R E, American Fournal of Pathology, 1977, 87, 686.

${ }_{13}$ Parmley, T H, and Woodruff, J D, American fournal of Obstetrics and Gynecology, 1974, 120, 234.

14 Greenberg, $M$, and Lloyd Davies, T A, British fournal of Industrial Medicine, 1974, 31, 91.

${ }^{15}$ Newhouse, M L, et al, British fournal of Industrial Medicine, 1972, 29, 134

${ }^{16}$ Armstrong, B, and Doll, R, International fournal of Cancer, 1975, 15, 617.

17 Tillotson, J L, et al, American fournal of Clinical Nutrition, 1973, 26, 177. 